\title{
Zika Virus Baculovirus-Expressed Virus-Like Particles Induce Neutralizing Antibodies in Mice
}

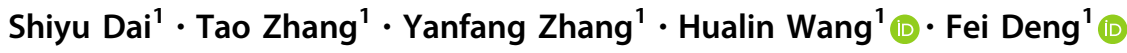

Received: 13 December 2017 / Accepted: 30 March 2018/Published online: 17 May 2018

(C) The Author(s) 2018

\begin{abstract}
The newly emerged mosquito-borne Zika virus (ZIKV) strains pose a global challenge owing to its ability to cause microcephaly and neurological disorders. Several ZIKV vaccine candidates have been proposed, including inactivated and live attenuated virus vaccines, vector-based vaccines, DNA and RNA vaccines. These have been shown to be efficacious in preclinical studies in mice and nonhuman primates, but their use will potentially be a threat to immunocompromised individuals and pregnant women. Virus-like particles (VLPs) are empty particles composed merely of viral proteins, which can serve as a safe and valuable tool for clinical prevention and treatment strategies. In this study, we used a new strategy to produce ZIKV VLPs based on the baculovirus expression system and demonstrated the feasibility of their use as a vaccine candidate. The pre-membrane (prM) and envelope (E) proteins were co-expressed in insect cells and selfassembled into particles similar to ZIKV. We found that the ZIKV VLPs could be quickly and easily prepared in large quantities using this system. The VLPs were shown to have good immunogenicity in immunized mice, as they stimulated high levels of virus neutralizing antibody titers, ZIKV-specific IgG titers and potent memory $\mathrm{T}$ cell responses. Thus, the baculovirus-based ZIKV VLP vaccine is a safe, effective and economical vaccine candidate for use against ZIKV.
\end{abstract}

Keywords ZIKV · Baculovirus expression system · Virus-like particles (VLPs) · Neutralizing antibodies

\section{Introduction}

Zika virus (ZIKV), first discovered in 1947 (Dick et al. 1952), is a mosquito-borne flavivirus and has posed a great threat to public health over the past three decades (Lessler et al. 2016). It has been reported that ZIKV infection is associated with microcephaly and serious neurological complications, such as Guillain-Barre syndrome (Mlakar et al. 2016; Miner et al. 2016). There are no specific vaccines or drugs available; thus, the rapid development of a safe and effective vaccine is a high priority.

Zika viruses are spherical virions that package a singlestranded, positive-sense RNA genome complexed with

\footnotetext{
Hualin Wang

h.wang@wh.iov.cn

df@wh.iov.cn

1 State Key Laboratory of Virology, Wuhan Institute of Virology, Chinese Academy of Sciences, Wuhan 430071, China
}

$\bowtie$ Fei Deng multiple copies of the capsid protein (C), surrounded by a host-derived lipid envelope that involves two viral structural proteins: the pre-membrane/membrane (prM/M) and envelope (E) proteins (Heinz and Stiasny 2012). Highresolution structures of mature/immature ZIKV and the ectodomain of the $\mathrm{E}$ protein have revealed that ZIKV displays a similar structure to other known flaviviruses (Sirohi et al. 2016; Prasad et al. 2017; Dai et al. 2016).

During infection of host cells, the viral genome is translated in the cytoplasm of host cells as a single open reading frame that is subsequently cleaved into three structural proteins (C, prM and E) and seven non-structural proteins by viral and host proteases (Heinz and Stiasny 2012). The new virions assemble in the endoplasmic reticulum (ER) and bud as non-infectious immature particles consisting of 60 trimeric spikes of E-prM heterodimers (Zhang et al. 2003). They are transported through the exocytic pathway of host cell until they reach the transGolgi network (TGN). In the low-pH environment of TGN, the E-prM heterodimers are reorganized into E homodimers (Yu et al. 2008) and the cleavage site of prM is 
exposed for digestion by a host furin-like protease. After prM is cleaved, the virions become infectious mature particles composed of 180 copies of the $\mathrm{E}$ and $\mathrm{M}$ proteins on the envelope. Subsequently, the newly synthesized virions are transported to the cell surface for exocytosis.

The $\mathrm{E}$ glycoprotein is involved in receptor binding, attachment and virus fusion during cell entry, and it represents a major target for neutralizing antibodies, which play a critical role in protection against flaviviruses (Heinz and Stiasny 2012). Thus, the E protein is the primary antigen for ZIKV vaccine development. Neutralization studies of ZIKV-confirmed convalescent human serum or plasma samples indicate that the different lineages of ZIKV represent a single serotype, with little antigenic variation and high sequence homology, suggesting that antigens produced from one lineage would provide protection against all contemporary circulating strains (Dowd et al. 2016a). Recently, the development of ZIKV vaccines has been accelerated by the exploration of various antigendelivery approaches, including inactivated and live attenuated virus vaccines, DNA vaccines, RNA vaccines, protein subunits and other viral vectors-based vaccines. These candidates have been shown to provide protection against ZIKV challenge in mice and nonhuman primates (Pierson and Graham 2016; Durbin 2016; Abbink et al. 2016; Larocca et al. 2016; Pardi et al. 2017; Shan et al. 2017; Dowd et al. 2016b), and some have entered early clinical trials. However, safety concerns may limit the licensing of these ZIKV vaccine candidates.

Virus-like particles (VLPs) are empty, multi-protein structures resembling native virions, but they are noninfectious due to a lack of viral genetic material (RodriguezLimas et al. 2013). The antigens are present in their native conformation (without involving a replicating virus). VLPs can serve as excellent platforms for the development of efficient vaccines, since they have the ability to induce strong humoral and cellular responses, allow rapid testing of multiple candidate antigen designs and are associated with a safer manufacturing process (Liu et al. 2016). Studies of ZIKV (Boigard et al. 2017; Yang et al. 2017; Garg et al. 2017) and other flaviviruses, such as tick-borne encephalitis virus (TBEV) (Allison et al. 1995), dengue fever virus (DENV) (Shang et al. 2012) and Japanese encephalitis virus (JEV) (Du et al. 2015), have showed that expression of the structural proteins prM and $\mathrm{E}$ is sufficient for the assembly and release of VLPs that are morphologically and antigenically similar to the native virions. ZIKV VLPs have been studied in mammalian cells (Boigard et al. 2017; Garg et al. 2017) and plants (Yang et al. 2017), and these studies showed that coexpressing the structural (CprME) and non-structural (NS2B/ NS3) proteins, or displaying the ZIKV E protein domain III on VLPs based on the hepatitis B core antigen ( $\mathrm{HBcAg}$ ), stimulated immunized mice to generate high levels of virus neutralizing antibody (NAb) titers. In addition to mammalian cells and plants, baculovirus-insect cell systems are extensively utilized for VLP production due to a number of advantages, such as lower costs, large-scale cultivation capacity, post-translational modification of the recombinant proteins that is similar to mammalian cells and the rapid growth of insect cells in animal-product-free media, which prevents contamination by mammalian pathogens (Zeltins 2013).

In this study, we introduced a method to construct ZIKV VLPs based on the baculovirus expression system. Coexpression of the prM and $\mathrm{E}$ proteins in insect cells enabled the formation of VLPs that were similar to ZIKV virions. The VLPs represent a promising vaccine candidate due to their potential to induce immune responses in mice.

\section{Materials and Methods}

\section{Cells and Viruses}

Vero cells were obtained from the American Type Culture Collection (ATCC, Manassas, VA, USA), and grown in Dulbecco's modified Eagle's medium (DMEM) supplemented with $10 \%$ fetal bovine serum (FBS; Gibco, Grand Island, NY, USA) at $37{ }^{\circ} \mathrm{C}$ in $5 \% \mathrm{CO}_{2}$. Spodoptera frugiperda $\mathrm{Sf} 9$ cells were cultured in Grace's insect medium (Gibco, Grand Island, NY, USA), pH 6.0, supplemented with $10 \%$ FBS at $27^{\circ} \mathrm{C}$. The ZIKV strain SZ-WIV01 (GenBank accession no.: KU963796), which was isolated from the serum of an imported ZIKV case in China (Deng et al. 2016), was obtained from Microorganisms \& Viruses Culture Collection Centre (MVCCC) of Wuhan Institute of Virology. The virus was propagated in Vero cells and stored at $-80^{\circ} \mathrm{C}$. Virus titers were determined using Vero cells by the microtitration method, and they were expressed as the $50 \%$ tissue culture infective dose $\left(\mathrm{TCID}_{50}\right)$ according to the Reed-Muench method.

\section{Construction of Recombinant Baculovirus}

The genomic RNA of the ZIKV strain SZ-WIV01 was extracted from infected Vero cells using TRIzol regent (Invitrogen, Carlsbad, CA, USA), and subsequently reverse transcribed using Moloney Murine Leukemia Virus (MMLV) Reverse Transcriptase (Promega, Madison, WI, USA) according to the manufacturer's instructions. The resultant cDNA was used as a template for the amplification of gene fragments coding for prME using the following primers: forward primer: 5'-CGGGATCC ATGGGCGCAGATACTAATGTCGG- ${ }^{\prime}{ }^{\prime}$ and reverse primer: 5'-CGGAATTCTTAAGCAGAGACGGCTGTGGA TAAG-3'. The forward primer contained a BamH I 
restriction site and the reverse primer contained an EcoR I restriction site for ligation to a $\mathrm{pFastBac}^{\mathrm{TM}}$ Dual vector (Invitrogen, Carlsbad, CA, USA) under the polyhedrin promoter $\left(\mathrm{P}_{\mathrm{PH}}\right)$, generating pFBD-prME. To ensure the correct translocation and proper translational processing of prME, the expression cassette of prME included the signal peptide (SP) sequence derived from the C-terminus of the capsid (C) protein, as previously reported (Du et al. 2015; Mani et al. 2013) (Fig. 1A). The construct was used to generate the corresponding baculovirus, namely vAcprME, using the Bac-to-bac system (Invitrogen, Carlsbad, CA, USA) according to the manufacturer's instructions. The baculovirus vAc-hsp70-egfp was previously constructed in our laboratory (Wang et al. 2008) and was used as a control baculovirus.

\section{Preparation of Polyclonal Antibodies}

The nucleotide sequences encoding the full-length $\mathrm{E}$ protein (504 aa) and prM protein (164 aa) were cloned into a pET32a vector (Novagen, Carlsbad, CA, USA). The corresponding His-tag fusion proteins were expressed in Escherichia coli BL21(DE3) and were purified by affinity chromatography using nickel-charged resin (Roche Diagnostics, Indianapolis, IN, USA). The purified proteins were used as antigens to generate rabbit polyclonal antiserum (anti-E and anti-prM) in our lab according to a previously reported method (Deng et al. 2007). Polyclonal antibodies (pAb) against GP64 and VP39 were also used (Wang et al. 2008).

\section{Western Blot Analysis of Protein Expression}

The Sf9 cells were infected with the recombinant baculovirus vAc-prME or the control baculovirus vAc-hsp70egfp at a multiplicity of infection (MOI) of 5, and the lysates were collected at $72 \mathrm{~h}$ post infection (h.p.i.) and prepared for sodium dodecyl sulfate polyacrylamide gel electrophoresis (SDS-PAGE), followed by transfer to polyvinylidene difluoride (PVDF) membranes (Millipore, Billerica, MA, USA). After blocking with Tris-buffered saline (TBS) containing 5\% nonfat milk, the membranes

A

(a)

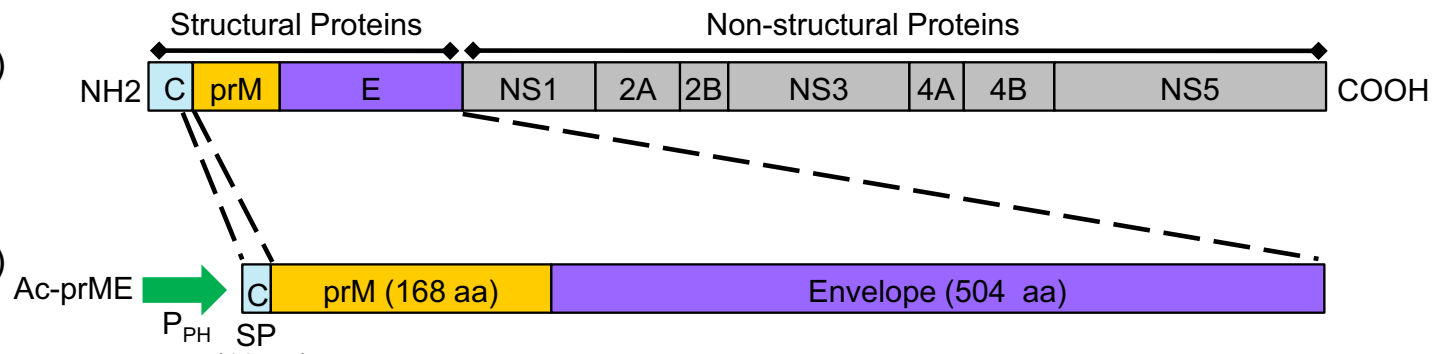

(18 aa)

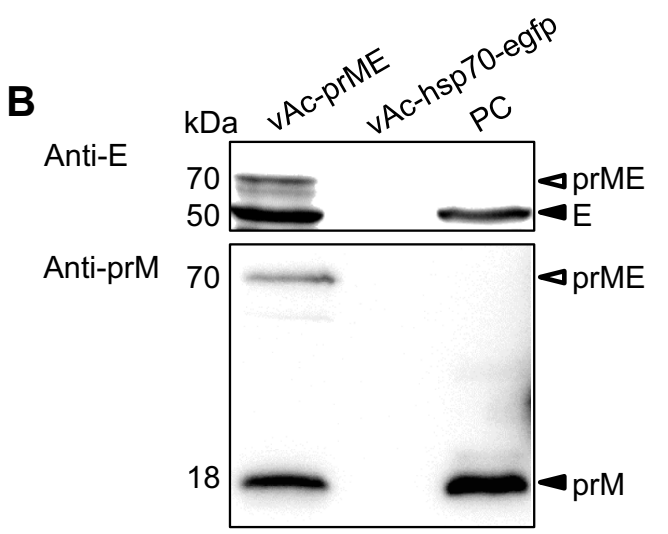

Fig. 1 A Construction of recombinant baculovirus. A-a Schematic representation of the ZIKV polyprotein. A-b Structure of recombinant bacmid encoding prME for the formation of VLP in Sf9 cells. Part of prME was inserted into AcMNPV bacmid under the control of a polyhedrin promoter $\left(\mathrm{P}_{\mathrm{PH}}\right)$, preceded by $18 \mathrm{C}$-terminal amino acid residues of the capsid protein as the signal peptide (SP), to ensure correct expression and transportation. B Western blot analysis of the prM and E proteins in Sf9 cells infected with the recombinant

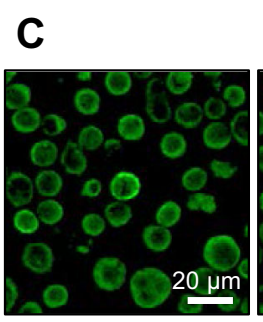

Anti-E

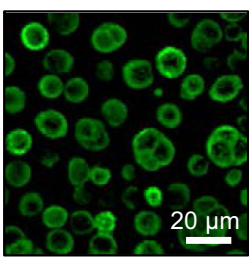

Anti-prM

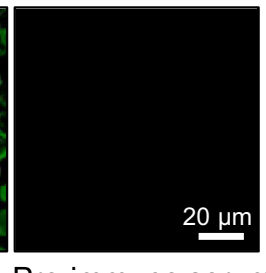

Pre-immune serum baculovirus vAc-prME, vAc-hsp70-egfp-infected cells were used as the negative control and the ZIKV-infected Vero cells were used as the positive control. The primary antibodies used for the upper and lower panels were anti-E and anti-prM polyclonal antibody respectively. Solid triangles indicate corresponding proteins, and hollow triangles indicate the uncleaved polyprotein, prME. C Immunofluorescence assay of the prM and $\mathrm{E}$ proteins in $\mathrm{Sf} 9$ cells infected with the recombinant baculovirus vAc-prME. Scale bars $=20 \mu \mathrm{m}$. 
were incubated with anti-E and anti-prM pAb as primary antibodies, and horseradish peroxidase (HRP)-conjugated goat anti-rabbit antibody (Sigma, St. Louis, MO, USA) as the secondary antibody. Protein band signals were detected using SuperSignal West Pico Chemiluminescent Substrate (Thermo Scientific, Rockford, IL, USA).

\section{Immunofluorescence}

Sf9 cells were infected with the recombinant baculovirus vAc-prME at an MOI of 5. At 72 h.p.i., the cells were fixed for $10 \mathrm{~min}$ with $4 \%$ paraformaldehyde-PBS. The fixed cells were incubated in $0.2 \%$ Triton X-100-PBS for permeabilization, and they were then blocked with $5 \%$ bovine serum albumin (BSA; Biosharp, Hefei, China). The cells were then treated with primary antibodies for $1 \mathrm{~h}$ at room temperature and stained with goat anti-rabbit IgGfluorescein isothiocyanate (FITC; Abcam, Cambridge, UK) for $1 \mathrm{~h}$ at room temperature. For visualization of the nuclei, the cells were incubated with Hoechst 33,258 (Beyotime, Shanghai, China) for $3 \mathrm{~min}$ at room temperature.

\section{Production and Purification of ZIKV Virions and ZIKV VLPs}

Vero cells were infected with ZIKV at an MOI of 0.1. The medium was collected 4 days post infection (d.p.i.), inactivated with $\beta$-propiolactone $(1: 4000 \mathrm{v} / \mathrm{v})$, cleared of cell debris and concentrated using tangential flow filtration. The sample was then loaded onto a discontinuous sucrose gradient $(20 \%, 50 \%)$ and subjected to ultracentrifugation at $150,000 \times g$ (SW41 rotor; Beckman, Fullerton, CA, USA) for $3 \mathrm{~h}$. The band between the surface of the $20 \%$ and $50 \%$ sucrose was then extracted and concentrated at 150,000 $\times g$ (SW41 rotor; Beckman) for $3 \mathrm{~h}$.

ZIKV VLPs were produced by Sf9 cells infected with the recombinant baculovirus vAc-prME at an MOI of 5. At 3 d.p.i., $100 \mathrm{~mL}$ cells $\left(2 \times 10^{6}\right.$ cells $\left./ \mathrm{mL}\right)$ were harvested by centrifugation at $3000 \times g$ for $5 \mathrm{~min}$ and resuspended in $10 \mathrm{~mL}$ cell lysis buffer (NaCl-Tris-Ethylenediaminetetraacetic acid [NTE] buffer, comprising $120 \mathrm{mmol} / \mathrm{L} \mathrm{NaCl}$, $10 \mathrm{mmol} / \mathrm{L} \mathrm{Tris}-\mathrm{HCl}$ and $1 \mathrm{mmol} / \mathrm{L}$ ethylenediaminetetraacetic acid [EDTA], pH 7.5), followed by sonication for $1 \mathrm{~min}$ and centrifugation at $13,000 \times g$ for $30 \mathrm{~min}$. The supernatant was passed through a $0.22-\mu \mathrm{m}$ filter to remove the debris and then concentrated using a $20 \%$ sucrose cushion at 150,000 $\times g$ (SW41 rotor; Beckman) for $3 \mathrm{~h}$. The pellets were resuspended in NTE buffer, sonicated for $30 \mathrm{~s}$ and subjected to a continuous sucrose gradient $(10 \%-$ $60 \%)$. After ultracentrifugation at $150,000 \times g(\mathrm{SW} 41$ rotor; Beckman) for $3 \mathrm{~h}, 12$ fractions were taken (from top to bottom) for western blot analysis and the $\mathrm{E}$ and prM antigen-enriched fractions were pelleted again at 150,000 $\times g$ (SW41 rotor; Beckman) for $3 \mathrm{~h}$. The pellets were resuspended in $100 \mu \mathrm{L}$ NTE buffer for subsequent transmission electron microscopy (TEM) assays.

\section{TEM and Immune-Electron Microscopy (IEM)}

To observe VLPs within cells, Sf9 cells were infected with vAc-prME at an MOI of 5. Infected cells were harvested at 72 h.p.i. and processed for electron microscopy as previously described (Vanlent et al. 1990) with slight modification. Sf9 cells infected with vAc-hsp70-egfp and healthy cells were used as controls.

After purification, the VLPs or ZIKV particles were adsorbed onto formvar-coated copper grids for $5 \mathrm{~min}$, negatively stained using $2 \%$ phosphotungstic acid (PTA) for $1 \mathrm{~min}$ and then examined with a transmission electron microscope (H-7000 FA; Hitachi, Japan).

For IEM, purified particles were adhered onto carboncoated nickel grids (200 mesh) and blocked with 5\% BSA. The primary antibodies were anti-prM and anti-E pAb and rabbit pre-immune serum. The 12-nm Colloidal GoldAffiniPure Goat Anti-Rabbit IgG (Jackson ImmunoResearch, West Grove, PA, USA) was used as the secondary antibody. Subsequently, the grids were negatively stained and examined with TEM as described above.

\section{Mice Immunizations}

Four groups of 6-8-week-old female BALB/c mice $(\mathrm{n}=6$ in each group) were vaccinated with $50 \mu \mathrm{g}$ ZIKV VLPs, $5 \mu \mathrm{g}$ purified inactivated ZIKV vaccine (designated PIV, for positive control), $50 \mu \mathrm{g}$ vAc-hsp70-egfp-infected Sf9 cell lysates (designated NC, for negative control; these cells were treated under exactly the same conditions as the ZIKV VLPs) or PBS (blank control). The level of $\mathrm{E}$ and prM proteins in purified inactivated ZIKV and VLPs used in a dose were analyzed by Western blot analysis and quantified by Image J software. All vaccines were adjuvanted with aluminum hydroxide (Thermo Fisher, Waltham, MA, USA) using a 1:1 volume ratio, and they were administered via the intramuscular (i.m.) route at weeks 0,2 and 4. Serum samples were taken before and 2 weeks after each vaccination to monitor the humoral immune response. All the animals were euthanized, and the splenocytes were harvested at week 6 for cellular immune response studies. The animal experiment procedures were approved by the ethics committees of Wuhan Institute of Virology, Chinese Academy of Sciences (approval number: WIVA33201601).

\section{Microneutralization Assay}

The neutralization test was carried out using a microneutralization assay in Vero cells. The sera were incubated at 
$56{ }^{\circ} \mathrm{C}$ for $30 \mathrm{~min}$ to inactivate the complement. Vero cells in 96-well plates were cultured overnight to $80 \%$ confluence. For each well, $50 \mu \mathrm{L}$ of a serial two-fold dilution of the serum was mixed with $50 \mu \mathrm{L}$ (equal volume) of 100 TCID50 of ZIKV and incubated at $37^{\circ} \mathrm{C}$ for $1 \mathrm{~h}$ to neutralize the infectious viruses. The mixtures were then transferred to the Vero cell monolayers. After incubation for 5 days at $37^{\circ} \mathrm{C}$, the NAb titer, defined as the highest dilution of serum that resulted in a $50 \%$ reduction in the cytopathic effect, was recorded.

\section{Serum Enzyme-Linked Immunosorbent Assay (ELISA)}

ZIKV-specific antibodies (IgG, IgG1, IgG2a, IgG2b, IgG2C, IgG3 and IgM) in sera were determined by ELISA. Microplates (Xiamen Labware, Xiamen, China) were coated with $50 \mu \mathrm{L} /$ well of purified and inactivated ZIKV $(2 \mu \mathrm{g} / \mathrm{mL})$ or VLPs $(5 \mu \mathrm{g} / \mathrm{mL})$ at $4{ }^{\circ} \mathrm{C}$ overnight. After extensive plate washing and blocking with $5 \%(\mathrm{w} / \mathrm{v}) \mathrm{BSA}$ in PBS with Tween 20 (PBST) for $1 \mathrm{~h}$ at $37{ }^{\circ} \mathrm{C}$, the serum was serially diluted and added to the wells in triplicate. Following $1 \mathrm{~h}$ incubation at $37^{\circ} \mathrm{C}$, the plates were washed and HRP-conjugated goat anti-mouse secondary antibodies (Jackson Immuno Research, West Grove, PA, USA) were added. After $1 \mathrm{~h}$ of incubation at $37{ }^{\circ} \mathrm{C}$, the plates were washed and developed by adding $100 \mu \mathrm{L} /$ well of $3,3^{\prime}, 5,5^{\prime}$ tetramethylbenzidine (TMB) substrate in the dark at room temperature for $20 \mathrm{~min}$ and stopped with $50 \mu \mathrm{L}$ of $2 \mathrm{~mol} / \mathrm{L}$ $\mathrm{H}_{2} \mathrm{SO}_{4}$. The optical density at $450 \mathrm{~nm}$ (OD450) of the plates was read using an ELISA plate reader (BioTek, USA). The titer for each group was determined as the reciprocal of the highest serum dilution with OD value $2 \sigma$ above the mean of the negative control.

\section{Cytokine Detection}

Memory immune response was measured at 2 weeks after the last immunization using a Mouse IFN- $\gamma$ Precoated ELISPOT kit (Dakewe Bioengineering, Beijing, China) according to the manufacturer's instructions. Briefly, $3 \times 10^{5}$ splenocytes/well (in duplicate) were cultured with inactivated ZIKV $(5 \mu \mathrm{g} / \mathrm{mL})$ or ZIKV VLPs $(10 \mu \mathrm{g} / \mathrm{mL})$ as an antigenic stimulator. Phorbol 12-myristate 13-acetate (PMA; $50 \mathrm{ng} / \mathrm{mL})$ with ionomycin $(1 \mu \mathrm{g} / \mathrm{mL})$ was used as the positive control. Spots were counted using a BioReader (ByoSys, German).

To detect cytokine production, $2 \times 10^{6}$ splenocytes/ well were cultured in 24-well plates with $0.5 \mathrm{~mL}$ Roswell Park Memorial Institute (RPMI) 1640 medium (containing $10 \%$ FBS $)$ and stimulated with ZIKV $(5 \mu \mathrm{g} / \mathrm{mL})$ or ZIKV VLPs $(10 \mu \mathrm{g} / \mathrm{mL})$. After incubation at $37{ }^{\circ} \mathrm{C}$ for $48 \mathrm{~h}$, the media were collected, softly centrifuged at $1000 \mathrm{rpm}$ for
$5 \mathrm{~min}$ and assayed for interferon (IFN)- $\gamma$, interleukin (IL)2, IL-4 and IL-10 production using commercially available ELISA kits (4A Biotech, Beijing, China). All the assays were performed in triplicate.

\section{Statistics Analysis}

For the statistical analysis of antibody titers, the titers were first transformed to $\log 10$.

Data are shown as the mean \pm standard deviations (SD) of six mice per group. Statistical significance was determined by Student's $t$ test, with $P$ value $<0.05$ considered to be statistically significant.

\section{Results}

\section{Recombinant Baculovirus Expressing ZIKV Proteins}

The DNA fragment encoding ZIKV prME was inserted into AcMNPV bacmid under the control of the polyhedrin promoter, which generated the recombinant bacmid AcprME (Fig. 1A). After transfection and infection, the recombinant baculovirus, vAc-prME, was generated and confirmed using western blot and immunofluorescence assays (IFA) (Fig. 1) using specific antibodies. As shown in Fig. 1B, separate bands corresponding to prM (18 kDa) and $\mathrm{E}(50 \mathrm{kDa})$ proteins were detected, indicating that digestion processing performed by host cell signalase had indeed occurred at the native cleavage site. In addition, a $70-\mathrm{kDa}$ band corresponding to the uncleaved polyprotein prME was also detected. In the ZIKV infected Vero cells, which were used as positive control, the prME band was not detected. This could because the cleavage of prME in ZIKV-sensitive Vero cells is more efficient and complete.

\section{ZIKV VLPs Were Generated by the Baculovirus Expression System}

The Sf9 cells infected with the recombinant baculovirus vAc-prME were harvested at 72 h.p.i. and observed using TEM. As indicated in Fig. 2A, Sf9 cells infected with vAcprME had vesicles full of spherical particles ranging from 50 to $100 \mathrm{~nm}$ in diameter, which were presumed to be VLPs, and some particles were released from the cell surface, similar to the native ZIKV exocytosis process from Vero cells (Fig. 2B). In contrast, Sf9 cells infected with vAc-hsp70-egfp and healthy Sf9 cells had empty vesicles or no vesicle (Fig. 2C).

Lysates of vAc-prME-infected Sf9 cells were layered onto the $10 \%-60 \%$ sucrose gradients and subjected to ultracentrifugation. After ultracentrifugation, 12 fractions 


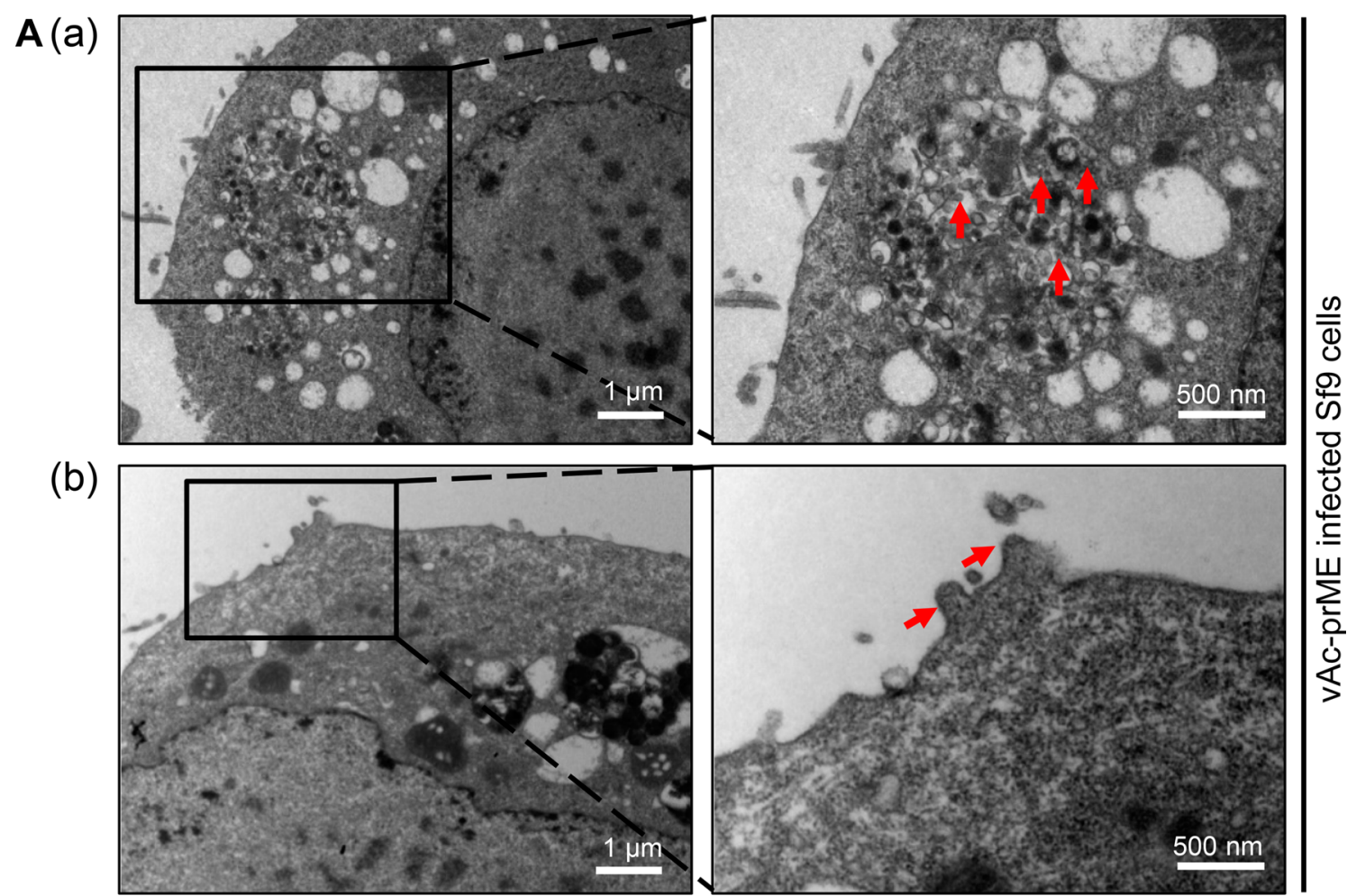

B
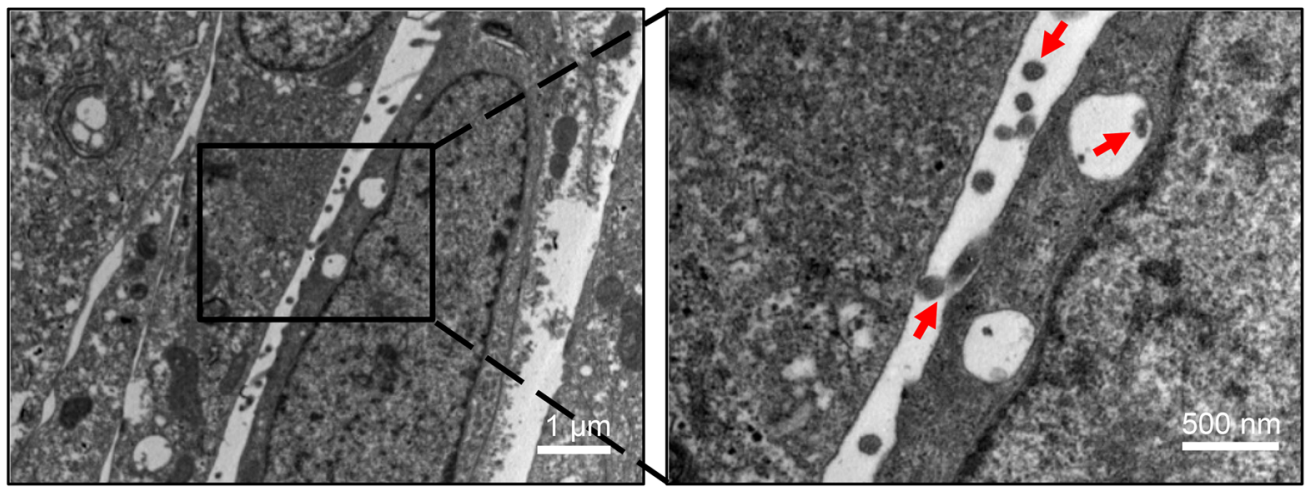

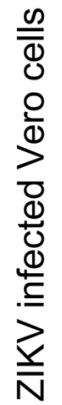

C
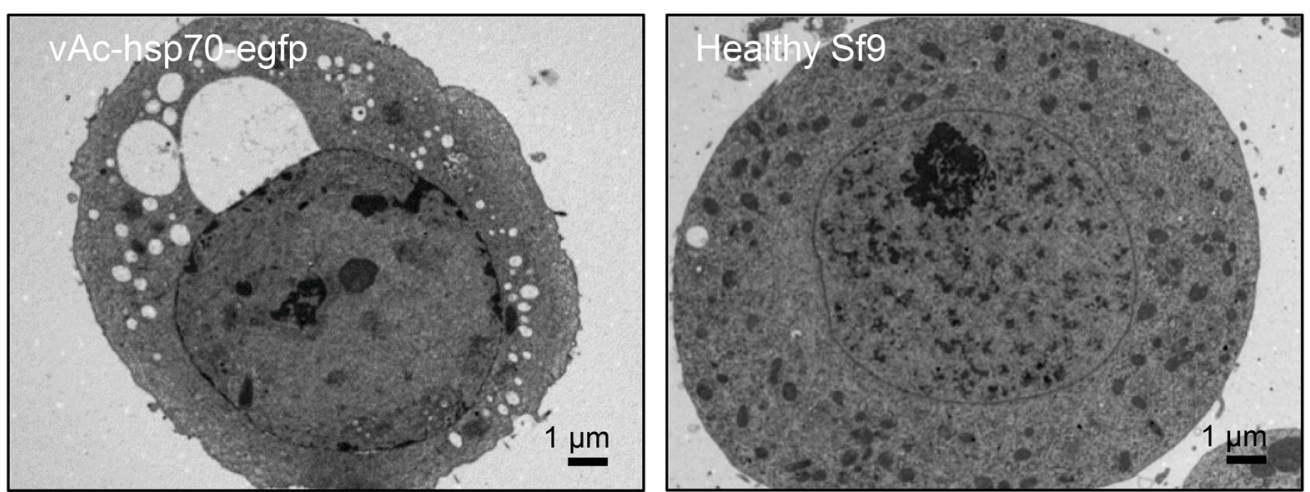

Fig. 2 Ultrathin sections of vAc-prME-infected Sf9 cells and ZIKVinfected Vero cells. A Transmission electron micrographs of Sf9 cells infected with vAc-prME. A-a Vesicles filled with small spherical particles (identified by the arrows) in Sf9 cells infected with vAcprME. A-b Spherical particles presumed to be ZIKV VLPs budding from the cell membrane. B Transmission electron micrographs of

Vero cells infected with ZIKV. The virions bud from the cell membrane. C Transmission electron micrographs of $\mathrm{Sf} 9$ cells infected with vAc-hsp70-egfp and healthy Sf9 cells. For $\mathbf{A}$ and $\mathbf{B}$, the right panels show enlarged views of the boxed regions in the corresponding left panels. 
were taken (from top to bottom) for western blot analysis. As shown in Fig. 3A, 3B, ZIKV-specific antigens were distributed across the sucrose gradient, from $30 \%$ to $60 \%$. Electron microscopic analysis of negative-stained purified ZIKV-antigen-rich fractions from the vAcprME-infected Sf9 cell lysates revealed rough spherical particles of $30-50 \mathrm{~nm}$ in size, which resembled native ZIKV virions in morphology (Fig. 3C). IEM using antiE/anti-prM antibodies further revealed immunogold particles surrounding distinct particles, which were similar to native virions (Fig. 3C), indicating the exposure of E and prM on the outer surface of the VLPs. All these data demonstrate that ZIKV VLPs comprising prM and E proteins can be assembled in Sf9 cells infected with vAc-prME and purified from the lysates by sucrose gradient ultracentrifugation.

\section{ZIKV VLPs Elicited Neutralizing Antibodies and Virus-Specific IgG}

$\mathrm{BALB} / \mathrm{c}$ mice were immunized via the i.m. route three times at 2-week intervals with VLPs or the control immunizations (i.e., the positive control involving purified inactivated $\mathrm{ZIKV}$, the negative control involving vAchsp70-egfp-infected Sf9 cell lysates or the blank control involving PBS). Based on the gray intensity of the bands in the Western blot analysis, the doses of $\mathrm{E}$ and prM proteins in PIV relative to VLP used to immunize mice were relevant as ratio of 1.11: 1 and 1.21: 1 respectively (Fig. 4A). Serum samples were collected at 2 weeks after each immunization, and evaluated for humoral immune responses induced by VLPs and control vaccinations.
A

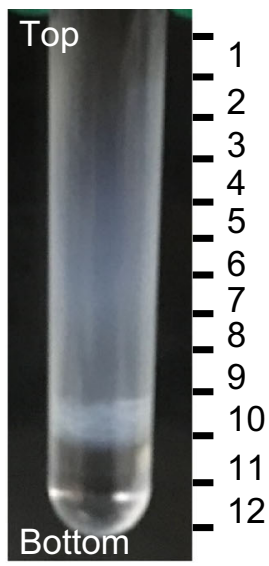

Fractions

C

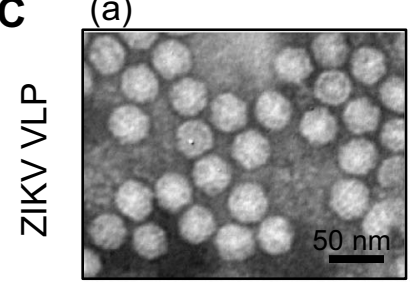

(e)

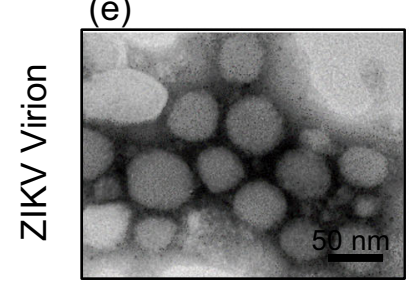

B

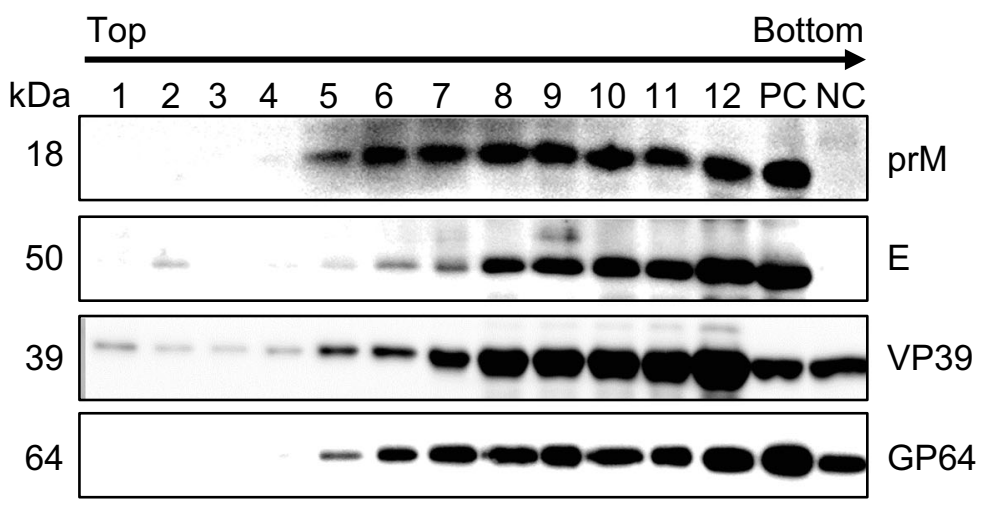

(b)

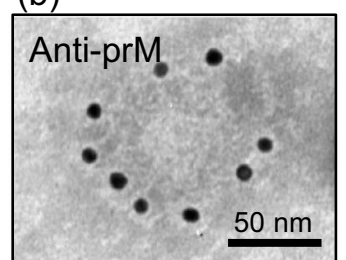

(f)

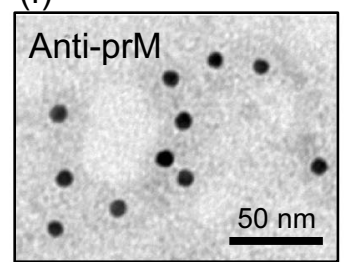

(c)

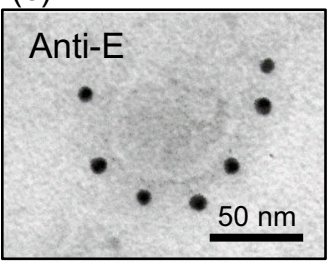

(g)

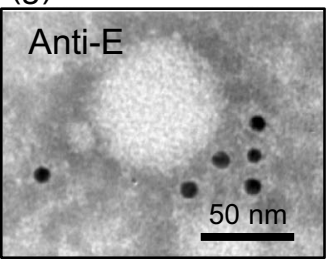

(d)

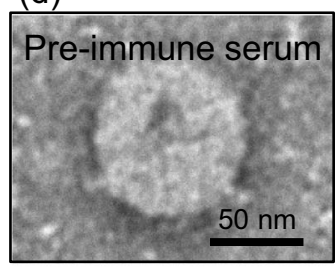

(h)

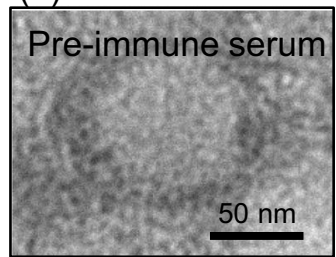

Fig. 3 Characterization of baculovirus-expressed ZIKV VLPs. A Lysates of vAc-prME-infected Sf9 cells were layered onto 10\%$60 \%$ sucrose gradients and subjected to centrifugation. Twelve fractions were taken from top to bottom. B Western blot analysis of purified sucrose gradient fractions using the indicated antibodies. C Electron micrographs of negative staining and immunogold labeling of VLPs and ZIKV. C-a Negative staining of purified ZIKV
VLPs from the $\mathrm{E}$ and prM antigen-enriched fractions from the sucrose gradient; IEM of VLPs using anti-prM $\mathbf{C}-\mathbf{b}$, anti-E, $\mathbf{C}-\mathbf{c}$ polyclonal antibodies and rabbit pre-immune serum, $\mathbf{C}-\mathbf{d}$ as primary antibodies; C-e Negative staining of purified ZIKV; IEM of ZIKV using antiprM $\mathbf{C}-\mathbf{f}$, anti-E, $\mathbf{C}-\mathbf{g}$ polyclonal antibodies and rabbit pre-immune serum, $\mathbf{C}-\mathbf{h}$ as primary antibodies; Scale bars $=50 \mathrm{~nm}$. 
A

(a) Prime $1^{\text {st }}$ Boost $2^{\text {nd }}$ Boost Sacrificed

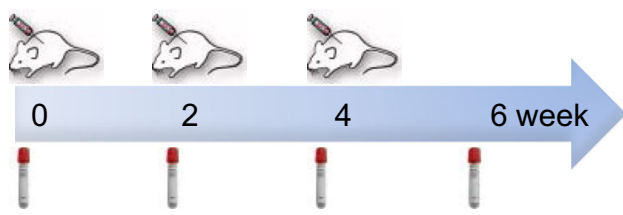

(b)
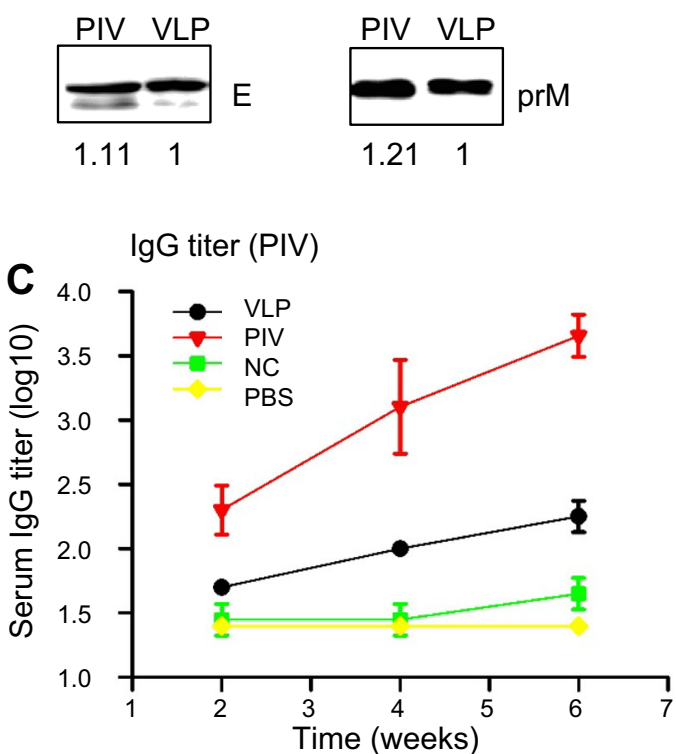

Fig. 4 Antibody responses elicited by ZIKV VLPs or control vaccinations. A A-a $B A L B / c$ mice $(n=6)$ were immunized with three doses of ZIKV VLPs (VLP), purified inactivated ZIKV vaccine (PIV), vAc-hsp70-egfp-infected Sf9 cell lysates (negative control, NC) or PBS at weeks 0,2 and 4. Blood samples were collected at weeks 0 (pre-immune serum), 2, 4 and 6 ( 2 weeks after each antigen injection). A-b The purified inactivated ZIKV and VLPs used in a dose $(5 \mu \mathrm{g}$ PIV and $50 \mu \mathrm{g}$ ZIKV VLPs) were analyzed by Western blot analysis and quantified by densitometry, the level of $\mathrm{E}$ (left

To demonstrate whether the antibodies induced by VLPs were able to neutralize live ZIKV, a microneutralization assay was carried out and the geometric mean titer (GMT) was calculated for each group (Fig. 4B). In VLP-immunized mice, neutralization titers after primary immunization were significantly increased compared with the preimmune serum (week 0). Antibody titers at week 6 ( 2 weeks after the second booster) were similar to those at week 4 ( 2 weeks after the first booster), suggesting that the last immunization did not significantly further boost the neutralization response. The neutralization titers elicited by VLPs were lower than those elicited by inactivated ZIKV, but significantly different from those elicited in the other two control groups.

As shown in Fig. 4C, 4D, when purified VLPs were used as the coating antigen, mice immunized with ZIKV VLPs

\section{B}
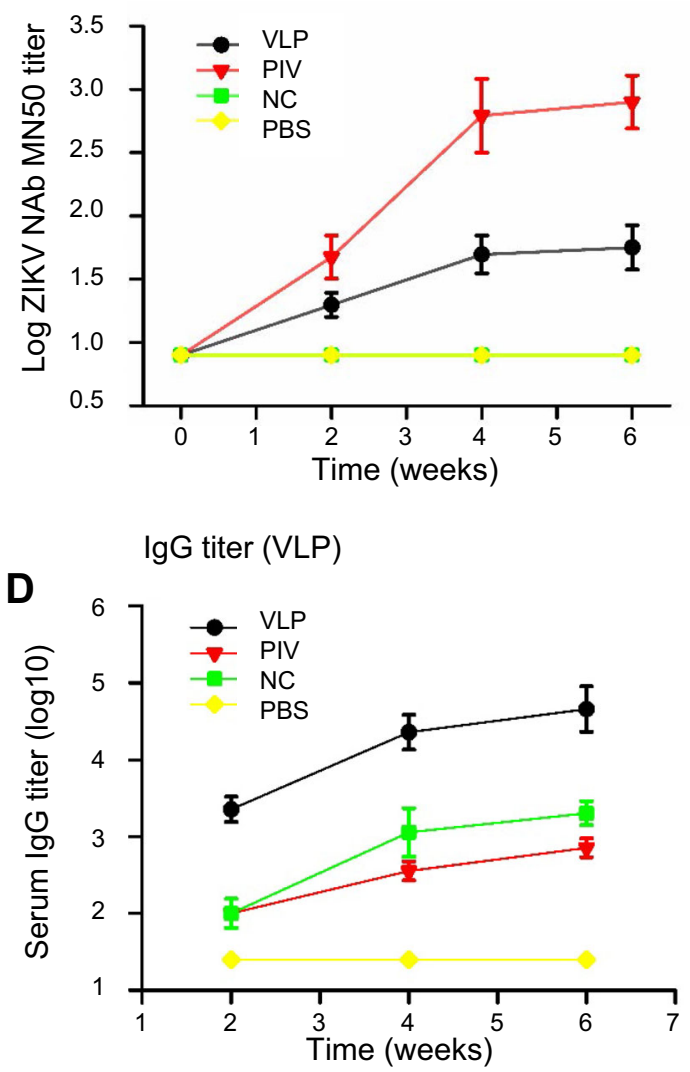

panel) and prM (right panel) proteins in PIV relative to VLP were 1.11: 1 and 1.21: 1. B Neutralization titers of the immunized mice determined by a microneutralization assay. C ZIKV-specific IgG titers and D VLP-specific IgG titers were measured via ELISA using two coating antigens: purified inactivated ZIKV or ZIKV VLPs. The values represent the mean $\pm S D$ of the reciprocal of the highest serial dilution (with an OD450 value $2 \sigma$ above the mean of the negative control) of six mice per group. The results of three independent experiments (with technical triplicates for each sample) are presented.

had a significantly higher level of specific serum $\operatorname{IgG}$ compared with the control mice. In addition, both inactivated ZIKV (positive control) and vAc-hsp70-egfp-infected Sf9 cell lysates (negative control) induced higher IgG responses than PBS (blank control). In account of the assembly process of VLPs, except for the specific ZIKV antigens, there should have some other proteins were packaged into or mixed with the VLPs, like the host cells proteins or baculovirus proteins, which may strengthen the immunogenicity of the VLPs. However, VLPs induced lower ZIKV-specific IgG titers than inactivated ZIKV when we used inactivated ZIKV as the coating antigen, yet, after immunization, the level was dramatically increased compared with the level in the other two control groups. Specific IgG titers were also lower when the plates were coated with inactivated ZIKV than VLPs. Since the ZIKV 
VLPs were co-purified with some process-related contaminants, which shown adjuvant activity and induced antibodies that were not specific to ZIKV. In the serum from mice immunized with ZIKV VLPs, antibodies could recognize the VLP antigens finely, but only the ZIKVspecific antibodies could react with the inactivated ZIKV antigens and led to low ZIKV-specific IgG titers. To further investigate the immune profiles induced, we analyzed the antibody subclasses in all immunized animals. Mice immunized with ZIKV VLPs or inactivated ZIKV induced evident $\operatorname{IgG} 1, \operatorname{IgG} 2 \mathrm{a}$ and $\operatorname{IgG} 2 \mathrm{~b}$ antibodies specific for ZIKV, but IgG2c, IgG3 and IgM antibodies were not detected at substantial levels (Fig. 5). The profile of IgG2a/ IgG1 was considered to be an indicator of the polarization of T helper (Th) 1 and Th2 cell-mediated immune responses. After primary immunization with VLPs, the IgG2a/ IgG1 isotype ratio was approximately 1.5 , suggesting that VLP immunization resulted in mostly the induction of Th1 cell-mediated immune responses. The two booster VLP immunizations increased the levels of both IgG1 and $\mathrm{IgG} 2 \mathrm{a}$, resulting in a decrease in the $\mathrm{IgG} 2 \mathrm{a} / \mathrm{IgG} 1$ ratio, indicating that the Th2 cell-mediated responses were also increased (Fig. 6). Overall, these results show that the VLPs were able to generate broadly ZIKV-specific antibodies capable of neutralization.

\section{ZIKV VLPs Induced Virus-Specific T cell Responses}

The responses of Th cells play an important role in generating both humoral and cellular immune responses. Th1cells are known to be involved in cell-mediated immunity, while Th2-cells function as helper T-cells in humoral

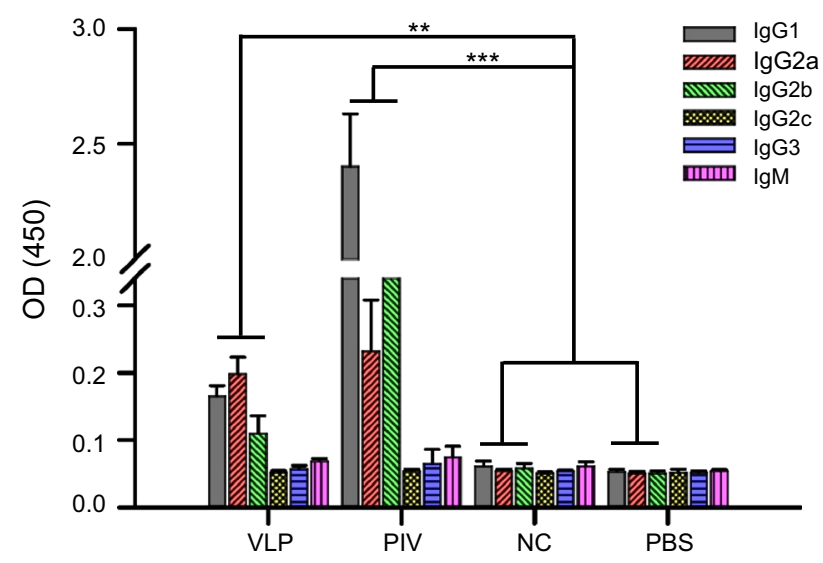

Fig. 5 Subclasses of antibody responses elicited by ZIKV VLPs or control vaccinations. ZIKV-specific subclass antibodies (IgG1, $\mathrm{IgG} 2 \mathrm{a}, \mathrm{IgG} 2 \mathrm{~b}, \mathrm{IgG} 2 \mathrm{c}, \mathrm{IgG} 3$ and $\mathrm{IgM})$ in all immunized mice were measured using ELISA. The sera were diluted at 1:400. The values represent the mean \pm SD of six mice per group. The results of three independent experiments (with technical triplicates for each sample) are presented. $* P<0.05$, $* * P<0.01 ; * * * P<0.001$. immunity (Ch'ng et al. 2011). To determine the ability of ZIKV VLPs to induce specific anti-ZIKV T cell immune responses, an enzyme-linked immunospot (ELISpot) assay for detecting IFN- $\gamma$-secreting cells was performed using splenocytes of immunized mice that were collected 2 weeks after the last immunization. As depicted in Fig. 7, splenocytes from mice immunized with ZIKV VLPs and inactivated ZIKV showed significantly higher levels of IFN- $\gamma$-secreting cell spots (in response to VLPs or inactivated ZIKV antigens) compared with both control groups (the vAc-hsp70-egfp and PBS groups). In addition, the number of IFN- $\gamma$-secreting cells detected among the splenocytes stimulated with VLPs was significantly higher than the number of spots detected among those stimulated with inactivated ZIKV for all groups of immunized mice apart from the inactivated ZIKV group (the positive control), as expected.

The production of cytokines by splenocytes was measured as indicators of the memory $\mathrm{T}$ cell response (Del Prete and Romagnani 1994). The Th1 (IFN- $\gamma$ and IL-2) and Th2 (IL-4 and IL-10) cytokines produced by splenocytes stimulated with VLPs or inactivated ZIKV were measured by ELISA. The results showed that splenocytes from the mice immunized with VLPs and inactivated ZIKV generated substantially higher levels of IFN- $\gamma$ and IL-2 than the levels in the other two control groups, indicating the induction of Th1 cell-mediated immune responses (Fig. 8A, 8B). The levels of IL-4 and IL-10 also indicated similar results (Fig. 8C, 8D), though the detection of IL-4 is generally difficult owing to its low expression levels. Th2 cell-mediated immune responses were also evoked. Furthermore, we found that in response to ZIKV antigens, the cytokines in inactivated ZIKV-immunized mice were higher than in VLP-immunized mice except for IL-10. All these results suggest that VLPs are able to induce memory $\mathrm{T}$ cell responses like inactivated ZIKV.

\section{Discussion}

Recently, several types of ZIKV vaccine candidates, including inactivated and live attenuated viruses, DNA and RNA vaccines, have been shown to have protective efficacy (Durbin and Wilder-Smith 2017). While these vaccine candidates show great promise, difficulties remain to be overcome regarding their licensing, especially on account of safety. The use of live viruses increases the risk of viral dissemination, and these vaccines increase the risk of side effects due to infection with viral nucleic acids. As alternative ZIKV vaccine platform, ZIKV VLPs have been produced in mammalian cells and plants and have been demonstrated to be potentially safe and effective (Boigard et al. 2017; Yang et al. 2017). VLPs are highly ordered 

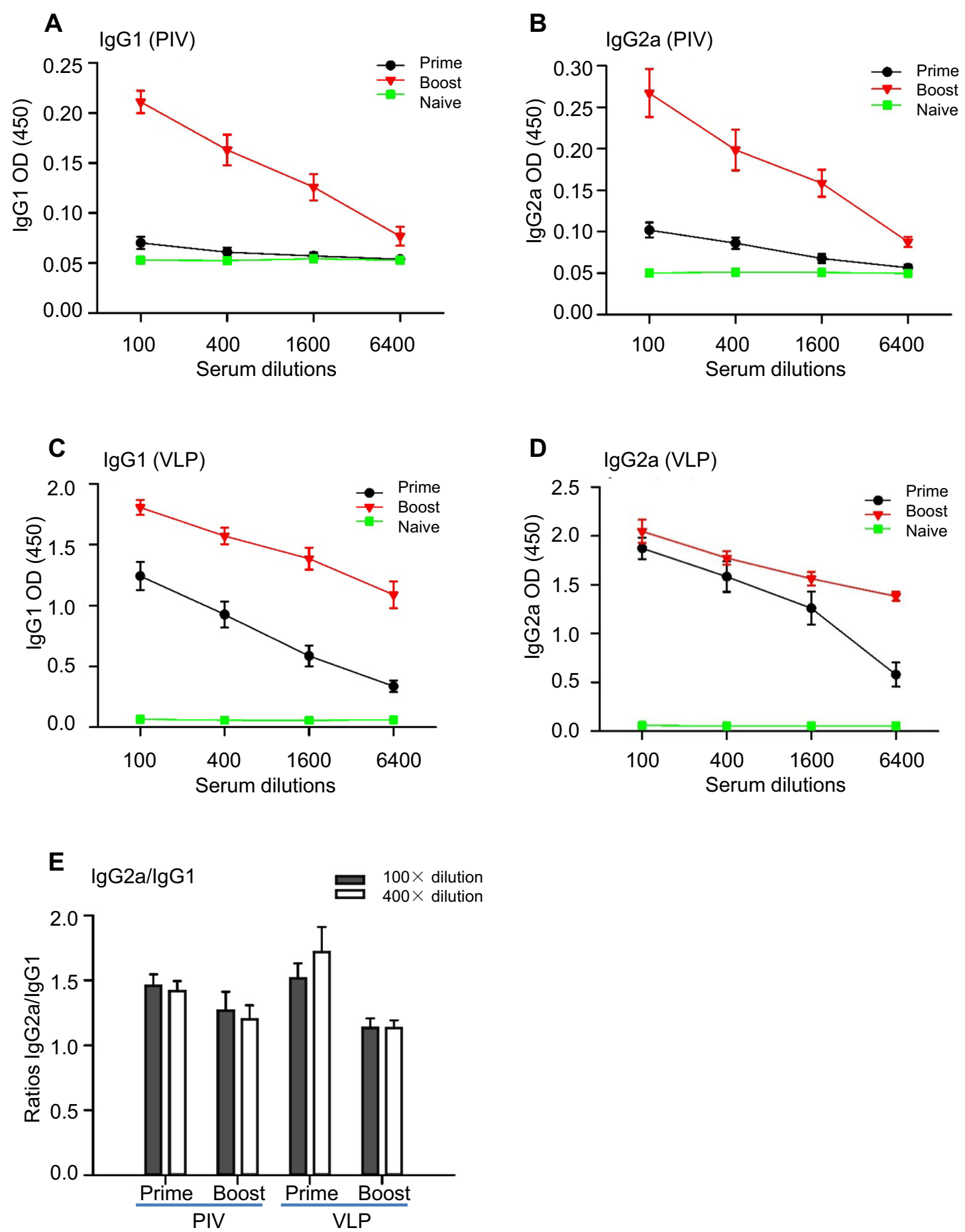

Fig. 6 Th1/Th2 IgG isotypes elicited by ZIKV VLPs. A ZIKVspecific IgG1 antibodies in ZIKV VLP-immunized mice. B ZIKVspecific IgG2a antibodies in ZIKV VLP-immunized mice. C VLPspecific IgG1 antibodies in ZIKV VLP-immunized mice. D VLPspecific IgG2a antibodies in ZIKV VLP-immunized mice. E Ratios of

multiprotein structures and carry many characteristics of viruses that can be used in vaccine development. Their good safety profile makes ZIKV VLPs an appropriate choice for immunocompromised individuals and pregnant
IgG2a to IgG1 antibodies in ZIKV VLP-immunized mice. The values represent the mean \pm SD of six mice. The results of three independent experiments (with technical triplicates for each sample) are presented.

women, as the World Health Organization has identified women of child-bearing age (including pregnant women) as the primary target population for ZIKV vaccination. Furthermore, VLPs have high immunogenicity and efficacy 


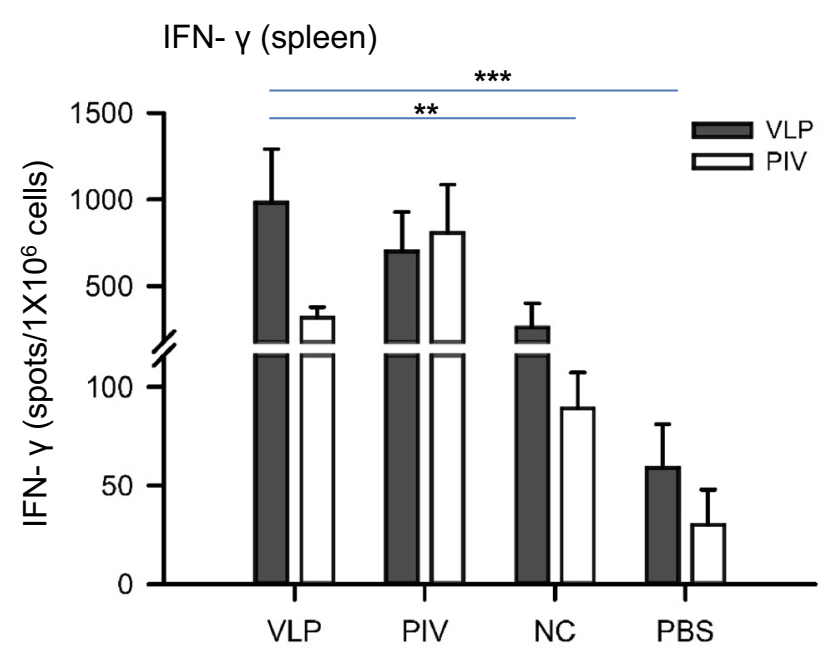

Fig. 7 IFN- $\gamma$-secreting memory splenocytes in immunized mice. All the mice were euthanized at week 6 (2 weeks after the last immunization), and the spleens were collected and assayed. Splenocytes were isolated and stimulated with $10 \mu \mathrm{g}$ purified ZIKV VLPs (VLP) or $5 \mu \mathrm{g}$ purified inactive ZIKV (PIV). IFN- $\gamma$-secreting cells were identified by ELISpots after stimulation. All data are presented as the mean $\pm \mathrm{SD}$ of six mice in each group. The results of two independent experiments (with technical duplicates for each sample) are presented. $* P<0.05, * * P<0.01 ; * * * P<0.001$.

due to their unique structures. Flavivirus infection usually elicits neutralizing antibodies that bind only to complex quaternary epitopes that are only displayed on intact particles, and not to recombinant monomeric E proteins (de Alwis et al. 2012). ZIKV VLPs display E proteins with proper folding and conformation, which means that they have advantages over subunit vaccines (such as the single E protein vaccine) regarding the induction of neutralizing antibodies.
In this study, we described a new strategy for generating ZIKV VLPs consisting of prM and E proteins in insect Sf9 cells using recombinant baculovirus, and these VLPs can potentially induce strong humoral and cellular immune responses in mice. The VLPs were efficiently isolated using sucrose gradient purification. TEM and IEM revealed that the VLPs appear as rough spherical particles and have similar morphology and antigenicity to native virions. However, the lack of an inner shell of capsid protein and the viral genome leads to a smaller size $(30-50 \mathrm{~nm})$ compared with native virions.

An animal experiment was performed to determine the immunogenicity and efficacy of this VLP-based vaccine, and a summary of the results is shown in Table 1 . The serum samples from the mice before and after immunization were assayed. The ZIKV-specific IgG and NAb levels obviously increased after immunization with VLPs. However, VLPs seemed to result in lower NAb titers than inactivated ZIKV. This may be partially due to the conformation of VLPs potentially being slightly different compared with the conformation of the authentic virus, as this conformational change may affect the neutralizing capacity and binding capacity to ZIKV. We also speculated that the ZIKV-specific antigens in our VLP vaccine were not as much as those in the inactivated virus vaccine and different vaccination dosage should be administered in further experiment. Moreover, an antibody subclass switch occurred, as demonstrated by the findings regarding the ZIKV-specific IgG subclasses in the serum. The ELISA results showed that in VLP-immunized mice, more IgG2a than IgG1 was initially produced. However, after two booster injections, the levels of both IgG2a and IgG1 isotypes increased and were not significantly different,
Table 1 Immune responses elicited by the VLP vaccine and controls

\begin{tabular}{lllll}
\hline & VLP & PIV & NC & PBS \\
\hline Dose $(\mu \mathrm{g})$ & 50 & 5 & 50 & - \\
NAb $(\log 10)$ & 1.8 & 2.9 & 0.9 & 0.9 \\
IgG $(\log 10)$ & $4.7 / 2.3$ & $2.9 / 3.7$ & $3.3 / 1.6$ & $1.4 / 1.4$ \\
IFN- $\gamma(\mathrm{spots})$ & $928 / 318$ & $702 / 803$ & $263 / 89$ & $59 / 30$ \\
IFN- $\gamma(\mathrm{pg} / \mathrm{mL})$ & $161.4 / 50.0$ & $58.2 / 97.0$ & $18.4 / 22.6$ & $5.7 / 7.3$ \\
IL-2 $(\mathrm{pg} / \mathrm{mL})$ & $403.9 / 93.5$ & $285.2 / 191.7$ & $98.8 / 15.1$ & $9.8 / 7.0$ \\
IL-4 $(\mathrm{pg} / \mathrm{mL})$ & $31.7 / 13.7$ & $23.4 / 29.0$ & $13.7 / 3.9$ & $3.5 / 3.1$ \\
IL-10 $(\mathrm{pg} / \mathrm{mL})$ & $1915.1 / 1085.5$ & $668.7 / 714.0$ & $268.2 / 121.7$ & $59.2 / 36.9$ \\
\hline
\end{tabular}

VLP, ZIKV VLP vaccine; PIV, purified inactivated vaccine; NC, negative control (vAc-hsp70-egfp-infected Sf9 cell lysates); PBS, blank control. NAb and IgG show the geometric mean titers of neutralization and virus-specific titers in serum collected at week 6 . For IgG titers, the left values represent the VLPspecific IgG titers and the right values represent ZIKV-specific IgG titers. IFN- $\gamma$ (spots) indicates the number of IFN- $\gamma$-secreting splenocytes per $1 \times 10^{6}$ cells. For IFN- $\gamma$, IL-2, IL4 and IL-10, the left and right values represent the production stimulated by VLPs and inactivated ZIKV, respectively. $\mathrm{n}=6$ for all groups. 


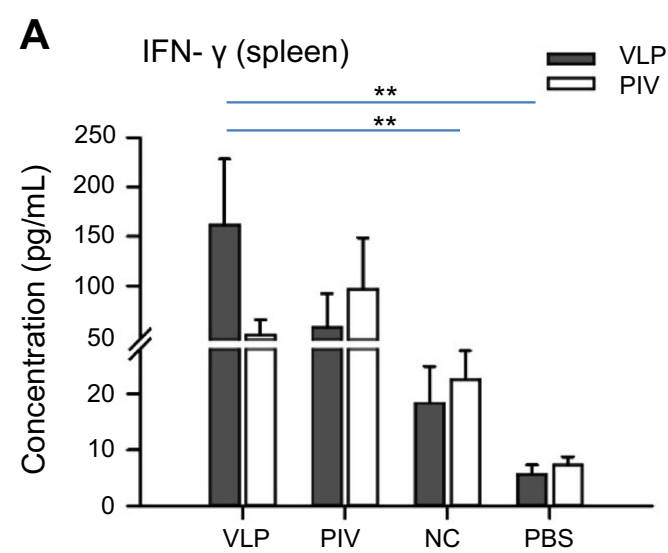

C

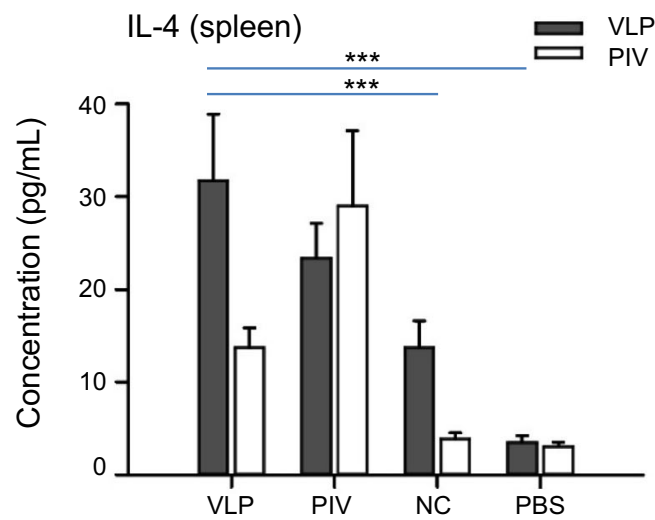

Fig. 8 Proliferation and cytokine production of splenocytes from immunized mice. Splenocytes were isolated and stimulated with $10 \mu \mathrm{g}$ purified ZIKV VLPs (VLP) or $5 \mu \mathrm{g}$ purified inactive ZIKV (PIV). The supernatants were then collected after $48 \mathrm{~h}$ of incubation and used to measure the concentrations of A IFN- $\gamma$, B IL-2, C IL-4

suggesting that booster immunizations led to memory B-cell activation and promote the Th1 immune response switch to a more balanced Th1/Th2 immune response. Immunization with VLPs also elicited robust memory $\mathrm{T}$ cell immune responses, which are important for viral clearance (Del Prete and Romagnani 1994). The production of high levels of Th1 type cytokines (IFN- $\gamma$ and IL-2) as well as Th2 type cytokines (IL-4 and IL-10) indicates that a mixed Th1/Th2 response was primed successfully by VLPs. All these results indicate that the VLP-based vaccine is highly immunogenic (inducing a wide-ranging and balanced immune response), however, the neutralization antibody titers and cytokine levels were relatively weak compared with those elicited by the inactivated virus. This may be due to the lack of proper protein processing and post translational modifications in the baculovirus-insect system, and the proper folding, especially glycosylation of viral antigens plays an important role in the efficacy of VLP-based vaccines as it is critical for immune recognition
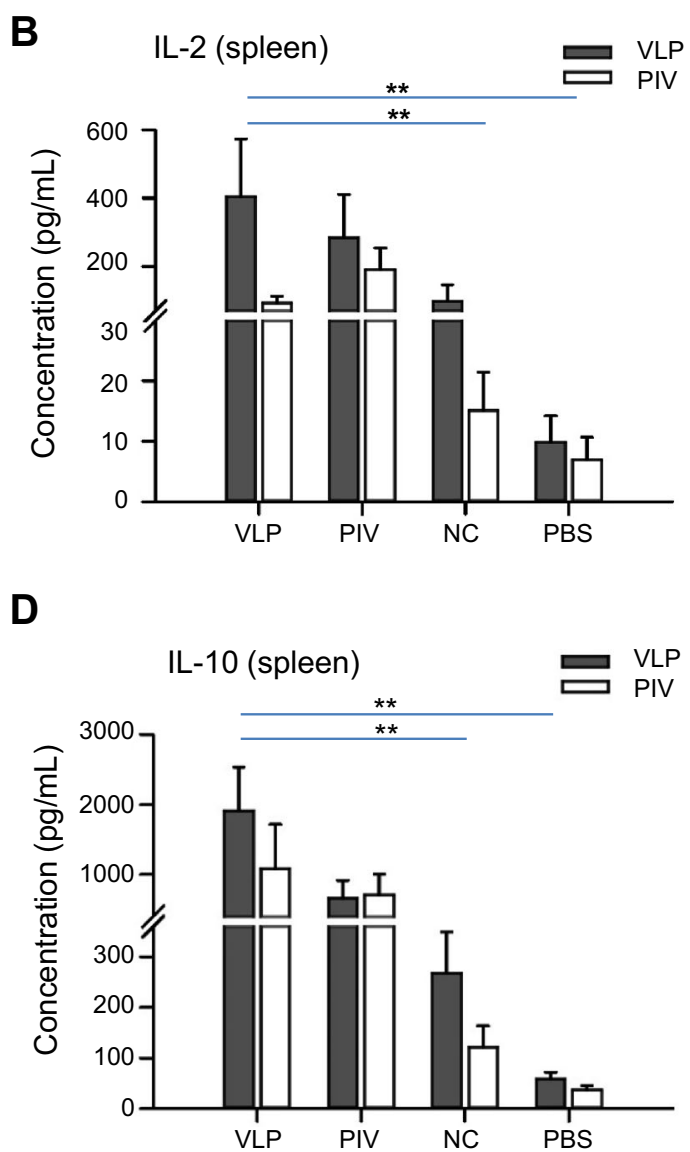

and D IL-10 using ELISA. All data are presented as the mean \pm SD of six mice in each group. The results of three independent experiments (with technical triplicates for each sample) are presented. $* P<0.05, * * P<0.01$; *** $P<0.001$.

(Rudd et al. 1999). However, lepidopteran cells are unable to produce glycoproteins with structurally authentic mammalian N-glycans (Jarvis 2003). Although the immune responses elicited by the VLPs are significantly weaker than those elicited by inactivated ZIKV, VLPs certainly represent a safer method of preventing ZIKV infection compared with other clinical prevention strategies. In addition, the VLP production process involving insect cells is low risk and fast. The protective immunity of the VLPs in vivo and the potential of the VLPs to induce antibodydependent enhancement of infection (ADE) will be investigated further in a suitable animal model, e.g., A129 (type I interferon receptor-deficient) or wild-type mice treated with an anti-IFNAR1 antibody.

We propose that ZIKV VLPs produced by insect cells using recombinant baculovirus should be further developed as a safe and effective vaccine candidate to protect humans against ZIKV outbreaks. 
Acknowledgements This work was supported by the Science and Technology Basic Work Program (2013FY113500) from the Ministry of Science and Technology of China, and the strategic priority research program of the Chinese Academy of Sciences (ZDRW-ZS2016-4). We acknowledge the Core Facility and Technical Support of Wuhan Institute of Virology for technical assistance.

Author Contributions HW and FD designed the experiments. SD and YZ carried out the experiments. SD and TZ analyzed the data. SD, HW and FD wrote the paper. All the authors approved the final manuscript.

\section{Compliance with Ethical Standards}

Conflict of interest The authors declared that they have no conflict of interests.

Animal and Human Rights Statement This study was approved of the Wuhan Institute of Virology, Chinese Academy of Sciences. All institutional and national guidelines for the care and use of animals were followed.

Open Access This article is distributed under the terms of the Creative Commons Attribution 4.0 International License (http://creative commons.org/licenses/by/4.0/), which permits unrestricted use, distribution, and reproduction in any medium, provided you give appropriate credit to the original author(s) and the source, provide a link to the Creative Commons license, and indicate if changes were made.

\section{References}

Abbink P, Larocca RA, De La Barrera RA, Bricault CA, Moseley ET, Boyd M, Kirilova M, Li Z, Ng'ang'a D, Nanayakkara O, Nityanandam R, Mercado NB, Borducchi EN, Agarwal A, Brinkman AL, Cabral C, Chandrashekar A, Giglio PB, Jetton D, Jimenez J, Lee BC, Mojta S, Molloy K, Shetty M, Neubauer GH, Stephenson KE, Peron JPS, Zanotto PMdA, Misamore J, Finneyfrock B, Lewis MG, Alter G, Modjarrad K, Jarman RG, Eckels KH, Michael NL, Thomas SJ, Barouch DH (2016) Protective efficacy of multiple vaccine platforms against Zika virus challenge in rhesus monkeys. Science 353:1129-1132

Allison SL, Stadler K, Mandl CW, Kunz C, Heinz FX (1995) Synthesis and secretion of recombinant tick-borne encephalitisvirus protein-e in soluble and particulate form. J Virol 69:5816-5820

Boigard H, Alimova A, Martin GR, Al K, Gottlieb P, Galarza JM (2017) Zika virus-like particle (VLP) based vaccine. PLoS Negl Trop Dis 11:e0005608

Ch'ng WC, Saw WT, Yusoff K, Shafee N (2011) Immunogenicity of a truncated enterovirus 71 VP1 protein fused to a Newcastle disease virus nucleocapsid protein fragment in mice. Acta Virol 55:227-233

Dai L, Song J, Lu X, Deng YQ, Musyoki AM, Cheng H, Zhang Y, Yuan Y, Song H, Haywood J, Xiao H, Yan J, Shi Y, Qin CF, Qi J, Gao GF (2016) Structures of the Zika virus envelope protein and its complex with a flavivirus broadly protective antibody. Cell Host Microbe 19:696-704

de Alwis R, Smith SA, Olivarez NP, Messer WB, Huynh JP, Wahala WM, White LJ, Diamond MS, Baric RS, Crowe JE Jr, de Silva AM (2012) Identification of human neutralizing antibodies that bind to complex epitopes on dengue virions. Proc Natl Acad Sci USA 109:7439-7444
Del Prete G, Romagnani S (1994) The role of TH1 and TH2 subsets in human infectious diseases. Trends Microbiol 2:4-6

Deng F, Wang R, Fang M, Jiang Y, Xu X, Wang H, Chen X, Arif BM, Guo L, Wang H, Hu Z (2007) Proteomics analysis of Helicoverpa armigera single nucleocapsid nucleopolyhedrovirus identified two new occlusion-derived virus-associated proteins, HA44 and HA100. J Virol 81:9377-9385

Deng C, Liu S, Zhang Q, Xu M, Zhang H, Gu D, Shi L, He J, Xiao G, Zhang B (2016) Isolation and characterization of Zika virus imported to China using C6/36 mosquito cells. Virol Sin 31:176-179

Dick GWA, Kitchen SF, Haddow AJ (1952) Zika virus.I. isolations and serological specificity. Trans R Soc Trop Med Hyg 46:509-520

Dowd KA, DeMaso CR, Pelc RS, Speer SD, Smith ARY, Goo L, Platt DJ, Mascola JR, Graham BS, Mulligan MJ, Diamond MS, Ledgerwood JE, Pierson TC (2016a) Broadly neutralizing activity of Zika virus-immune sera identifies a single viral serotype. Cell Rep 16:1485-1491

Dowd KA, Ko SY, Morabito KM, Yang ES, Pelc RS, DeMaso CR, Castilho LR, Abbink P, Boyd M, Nityanandam R, Gordon DN, Gallagher JR, Chen X, Todd JP, Tsybovsky Y, Harris A, Huang Y-JS, Higgs S, Vanlandingham DL, Andersen H, Lewis MG, De La Barrera R, Eckels KH, Jarman RG, Nason MC, Barouch DH, Roederer M, Kong WP, Mascola JR, Pierson TC, Graham BS (2016b) Rapid development of a DNA vaccine for Zika virus. Science 354:237-240

Du R, Yin F, Wang M, Hu Z, Wang H, Deng F (2015) Glycoprotein E of the Japanese encephalitis virus forms virus-like particles and induces syncytia when expressed by a baculovirus. J Gen Virol 96:1006-1014

Durbin A (2016) Vaccine development for Zika virus-timelines and strategies. Semin Reprod Med 34:299-304

Durbin A, Wilder-Smith A (2017) An update on Zika vaccine developments. Expert Rev Vaccines 16:781-787

Garg H, Sedano M, Plata G, Punke EB, Joshi A (2017) Development of virus-like-particle vaccine and reporter assay for Zika virus. J Virol 91:e00834-17

Heinz FX, Stiasny K (2012) Flaviviruses and their antigenic structure. J Clin Virol 55:289-295

Jarvis DL (2003) Developing baculovirus-insect cell expression systems for humanized recombinant glycoprotein production. Virology 310:1-7

Larocca RA, Abbink P, Peron JPS, Zanotto PMdA, Iampietro MJ, Badamchi-Zadeh A, Boyd M, Ng'ang'a D, Kirilova M, Nityanandam R, Mercado NB, Li Z, Moseley ET, Bricault CA, Borducchi EN, Giglio PB, Jetton D, Neubauer G, Nkolola JP, Maxfield LF, De La Barrera RA, Jarman RG, Eckels KH, Michael NL, Thomas SJ, Barouch DH (2016) Vaccine protection against Zika virus from Brazil. Nature 536:474-478

Lessler J, Chaisson LH, Kucirka LM, Bi Q, Grantz K, Salje H, Carcelen AC, Ott CT, Sheffield JS, Ferguson NM, Cummings DAT, Metcalf CJE, Rodriguez-Barraquer I (2016) Assessing the global threat from Zika virus. Science 353:aaf8160

Liu J, Dai S, Wang M, Hu Z, Wang H, Deng F (2016) Virus like particle-based vaccines against emerging infectious disease viruses. Virol Sin 31:279-287

Mani S, Tripathi L, Raut R, Tyagi P, Arora U, Barman T, Sood R, Galav A, Wahala W, de Silva A, Swaminathan S, Khanna N (2013) Pichia pastoris-expressed dengue 2 envelope forms viruslike particles without pre-membrane protein and induces high titer neutralizing antibodies. PLoS ONE 8:e64595

Miner JJ, Cao B, Govero J, Smith AM, Fernandez E, Cabrera OH, Garber C, Noll M, Klein RS, Noguchi KK, Mysorekar IU, Diamond MS (2016) Zika virus infection during pregnancy in 
mice causes placental damage and fetal demise. Cell 165:1080-1090

Mlakar J, Korva M, Tul N, Popovic M, Poljsak-Prijatelj M, Mraz J, Kolenc M, Rus KR, Vipotnik TV, Vodusek VF, Vizjak A, Pizem J, Petrovec M, Zupanc TA (2016) Zika virus associated with microcephaly. N Engl J Med 374:951-958

Pardi N, Hogan MJ, Pelc RS, Muramatsu H, Andersen H, DeMaso CR, Dowd KA, Sutherland LL, Scearce RM, Parks R, Wagner W, Granados A, Greenhouse J, Walker M, Willis E, Yu JS, McGee CE, Sempowski GD, Mui BL, Tam YK, Huang YJ, Vanlandingham D, Holmes VM, Balachandran H, Sahu S, Lifton M, Higgs S, Hensley SE, Madden TD, Hope MJ, Kariko K, Santra S, Graham BS, Lewis MG, Pierson TC, Haynes BF, Weissman D (2017) Zika virus protection by a single low-dose nucleoside-modified mRNA vaccination. Nature 543:248-251

Pierson TC, Graham BS (2016) Zika virus: immunity and vaccine development. Cell 167:625-631

Prasad VM, Miller AS, Klose T, Sirohi D, Buda G, Jiang W, Kuhn RJ, Rossmann MG (2017) Structure of the immature Zika virus at 9 A resolution. Nat Struct Mol Biol 24:184-186

Rodriguez-Limas WA, Sekar K, Tyo KE (2013) Virus-like particles: the future of microbial factories and cell-free systems as platforms for vaccine development. Curr Opin Biotechnol 24:1089-1093

Rudd PM, Wormald MR, Stanfield RL, Huang MD, Mattsson N, Speir JA, DiGennaro JA, Fetrow JS, Dwek RA, Wilson IA (1999) Roles for glycosylation of cell surface receptors involved in cellular immune recognition. J Mol Biol 293:351-366

Shan C, Muruato AE, Nunes BTD, Luo H, Xie X, Medeiros DBA, Wakamiya M, Tesh RB, Barrett AD, Wang T, Weaver SC, Vasconcelos PFC, Rossi SL, Shi PY (2017) A live-attenuated
Zika virus vaccine candidate induces sterilizing immunity in mouse models. Nat Med 23:763-767

Shang W, Liu J, Yang J, Hu Z, Rao X (2012) Dengue virus-like particles: construction and application. Appl Microbiol Biotechnol 94:39-46

Sirohi D, Chen Z, Sun L, Klose T, Pierson TC, Rossmann MG, Kuhn RJ (2016) The 3.8 angstrom resolution cryo-EM structure of Zika virus. Science 352:467-470

Vanlent JWM, Groenen JTM, Klingeroode EC, Rohrmann GF, Zuidema D, Vlak JM (1990) Localization of the $34 \mathrm{kda}$ polyhedron envelope protein in spodoptera-frugiperda cells infected with autographa-californica nuclear polyhedrosis-virus. Arch Virol 111:103-114

Wang M, Tan Y, Yin F, Deng F, Vlak JM, Hu Z, Wang H (2008) The F-like protein Ac23 enhances the infectivity of the budded virus of gp64-null Autographa californica multinucleocapsid nucleopolyhedrovirus pseudotyped with baculovirus envelope fusion protein F. J Virol 82:9800-9804

Yang M, Lai H, Sun H, Chen Q (2017) Virus-like particles that display Zika virus envelope protein domain III induce potent neutralizing immune responses in mice. Sci Rep 7:7679

Yu IM, Zhang W, Holdaway HA, Li L, Kostyuchenko VA, Chipman PR, Kuhn RJ, Rossmann MG, Chen J (2008) Structure of the immature dengue virus at low $\mathrm{pH}$ primes proteolytic maturation. Science 319:1834-1837

Zeltins A (2013) Construction and characterization of virus-like particles: a review. Mol Biotechnol 53:92-107

Zhang Y, Corver J, Chipman PR, Zhang W, Pletnev SV, Sedlak D, Baker TS, Strauss JH, Kuhn RJ, Rossmann MG (2003) Structures of immature flavivirus particles. EMBO J 22:2604-2613 